\title{
High Salt Diet Affects the Reproductive Health in Animals: An Overview
}

\author{
Sameh A. Abdelnour ${ }^{1}\left(\mathbb{D}\right.$, Mohamed E. Abd El-Hack ${ }^{2, *}{ }^{\mathbb{C}}$, Ahmed E. Noreldin ${ }^{3}{ }^{(D)}$, \\ Gaber Elsaber Batiha ${ }^{4,5}{ }^{\circ}$, Amani Magdy Beshbishy ${ }^{4}$, Husein Ohran ${ }^{6}$, Asmaa F. Khafaga ${ }^{7}$, \\ Sarah I. Othman ${ }^{8}$, Ahmed A. Allam ${ }^{9}$ and Ayman A. Swelum 10,11(D) \\ 1 Department of Animal Production, Faculty of Agriculture, Zagazig University, Zagazig 44511, Egypt; \\ samehtimor86@gmail.com \\ 2 Department of Poultry, Faculty of Agriculture, Zagazig University, Zagazig 44511, Egypt \\ 3 Histology and Cytology Department, Faculty of Veterinary Medicine, Damanhour University, \\ Damanhour 22511, Egypt; nourislam2010@yahoo.com \\ 4 National Research Center for Protozoan Diseases, Obihiro University of Agriculture and Veterinary \\ Medicine, Nishi 2-13, Inada-cho, 080-8555, Obihiro, Hokkaido, Japan; gaberbatiha@gmail.com (G.E.B.); \\ amanimagdi2008@gmail.com (A.M.B.) \\ 5 Department of Pharmacology and Therapeutics, Faculty of Veterinary Medicine, Damanhour University, \\ Damanhour 22511, AlBeheira, Egypt \\ 6 Department of Physiology, Veterinary Faculty, University of Sarajevo, Zmaja od Bosne 90, 71000 Sarajevo, \\ Bosnia and Herzegovina; husein.ohran@vfs.unsa.ba \\ 7 Department of Pathology, Faculty of Veterinary Medicine, Alexandria University, Edfina 22758, Egypt; \\ Asmaa.Khafaga@alexu.edu.eg \\ 8 Biology Department, Faculty of Science, Princess Nourah bint Abdulrahman University, \\ Riyadh 84428, Saudi Arabia; sialothman@pnu.edu.sa \\ 9 Department of Zoology, Faculty of Science, Beni-suef University, Beni-suef, 65211 Egypt; \\ allam1081981@yahoo.com \\ 10 Department of Animal Production, College of Food and Agriculture Sciences, King Saud University, P.O. \\ Box 2460, Riyadh 11451, Saudi Arabia (AAS); aswelum@ksu.edu.sa \\ 11 Department of Theriogenology, Faculty of Veterinary Medicine, Zagazig University, Zagazig 44511, Egypt \\ * Correspondence: dr.mohamed.e.abdalhaq@gmail.com
}

Received: 8 February 2020; Accepted: 23 March 2020; Published: 31 March 2020

\begin{abstract}
Salinity is a reliable issue of crop productivity loss in the world and in certain tropical and subtropical zones. However, tremendous progress in the genetic improvement of plants for salinity tolerance has been made over several decades. In light of this, halophytic plants can be used as animal feeds and have promising features because they are a good feed resource. However, the main constraint of saline pasture systems is the extreme concentration of $\mathrm{NaCl}$ salt in drinking water and forage plants for grazing animals. Ecological reports revealed that excess diet salt causes mortality and morbidity worldwide. Animal fed halophytic forages may have adverse effects on growth performance and reproductive function in males and females due to inducing reductions in hormone regulation, such as testosterone, $\mathrm{FSH}, \mathrm{LH}$, and leptin. It was indicated that high salt intake promotes circulating inflammatory factors in the placenta and is associated with adversative effects on pregnancy. This review focuses on the scientific evidence related to the effect of high salt intake on growth performance, spermatogenesis, sperm function, and testicular morphology changes in male animals. In addition, the review will also focus on its effect on some female reproductive features (e.g., ovarian follicle developments, placental indices, and granulosa cell function).
\end{abstract}

Keywords: high salt intake; reproductive health; animals; sperm function; ovarian follicles 


\section{Introduction}

With the rise of population in the world and decrease in the use of lands for agriculture practices, several approaches in agriculture systems involve the culture of plants in salinity land for animal feeding [1,2]. Moreover, many countries are suffering from scarcity of freshwater with an increase in the ambient temperature which had led to a decrease in the availability of freshwater. Recently, genetic scientists in the field of plants have produced some genetically modified plants, which could be able to grow in the salinity land. However, the main drawback of saline pasture systems is having the high salinity of drinking water and forage plants for grazing animals. Studies reported that the salt content of some forages such as Suaeda glauca has up to 317-331 g/kg dry matter (DM), while numerous other forages contain $15-41 \mathrm{~g} / \mathrm{kg}$ DM with higher than the salt content of $1.2-1.8 \mathrm{~g} / \mathrm{kg}$ DM in most forages [3]. Furthermore, surface water in saline regions comprises up to $0.9-1.7 \%$ salt, which leads to an exacerbation of the enhanced salt consumption [4]. Several types of animal disorders have been observed such as lipid accumulation, kidney damage, hypertension, and failure in renal function as a result of an excess intake of salt [5]. Moreover, nowadays, there is an increasing proof to examine the relation between high salt consumption and many disorders that include obesity, water retention, osteoporosis, cancer, obesity, vascular dementia, and diabetes [6-8]. Recently, increasing evidence revealed that a salt-rich diet stimulates the cytokine interleukine-17 in the gut, which leads to aberrant brain microvasculature, changed cognitive injury, and brain function [9]. Aguiar, et al. [10] indicated that high salt causes inflammation in mice's colonic mucosa through increased incidences of type 3 innate lymphoid cells (ILC3) and IL-23R+ CD4 + T cells and was reliant on interleukin-17 (IL-17). Moreover, the high prevalence of cardiovascular diseases has been related to excessive processed meat ingestion, partly due to higher salt intake. In vivo experiments have shown that a salt-rich diet possesses a negative impact on intestinal health, by inducing autoimmune disorders and tissue dysfunction [11].

Infertility potentially implicates several issues, but this review focuses mostly on the influences of high salt on the reproductive function in animals. Regarding the female animals, high salinity suppressed the recruitment and development of ovarian follicles, thereby increasing infertility [7]. Additionally, placental changes suggest that even modest dietary intakes of usually "Western" diet constituents can alter placental functions in ways that demonstrate placental failure [12]. Additionally, researches have recognized that high intake of salt has harmful effects irrespective of the increase in blood pressure, hypertension, and cardiovascular diseases [13,14]. According to previous facts, health associations have issued guidelines to minimize the consumption of salt $[15,16]$. Nevertheless, experimental reports did not explicitly indicate a health gain from such treatments, which posed concerns about the scientific data that supports the random limit of salt in the overall population $[17,18]$. Consequently, there has been a longstanding debate regarding the efficacy of reducing sodium intake and a call for further research to obtain a deeper understanding of its health and syndrome properties [19].

The examination of reproductive health in animals fed a high-salt diet revealed an impairment in sperm function, disturbances in hormonal regulation, reduced testicular weight, and alterations in testicular morphology and gene expression related to sperm quality in males [3]. Additionally, previous reports concluded that intake of halophytic forages might have deleterious influences on growth traits [3,20], milk production, and fetal development [4], through direct or indirect effects [3,21,22]. High salt intake disrupts the normal reproductive function in animals, which may manifest as decreased testes weight, sperm function, and sexual hormones in rams [3], and alters molecular transcripts for some related genes. High salt in water has been shown to decrease reproductive efficiency in relation to diets in males and young animals in contrast to females and adult animals.

This review intended to illustrate related studies concerning the possible hazards of dietary high-salt on growth rates, hormonal homeostasis, testicular morphology, sperm function, gene alteration related to spermatogenesis and maturation, and in vitro fertilization results in different males of animal species; furthermore, it summarizes the negative influences of high salt diets on female 
reproductive features, such as ovarian follicle developments, hormonal profile, placental indices, and granulosa function.

\section{Growth Performance}

Studies on animals revealed that high salt reduces the growth performance parameters: live body weight gain (LBWG), daily body weight gain (DBWG), and feed and water intake (FI and WI, respectively), and decrease the digestibility of nutrients $[3,20,23,24]$. On the other hand, some reports indicated that high salt consumption had no effects on LBWG, DBWG, and FI and WI) [25-27]. Rams exposed to $12 \%$ salt for three months had lower LBWG $(p<0.05)$ and higher WI $(p<0.05)$ relative to normal salt diet (4\%) [3]. In the study of Fang et al. [3], authors selected this level of salt based on the contents of salt in some forages which are normally grown on salt-tolerant grass, comprising Puccinellia tenuiflora, Leymus chinensis, Chloris, and Suaeda glauca, in Jilin province's western grassland [3]. The consumption of high salt diets resulted in lower growth performance in sheep [3], whereas LBWG was slower relative to high salt content [20]. One explanation for the disturbances in animal performance raised in the salt-land pasture has frequently been attributed to reduced FI and poor plant digestibility [23], it is more probable owing to excess sodium intake [28]. Results indicated that the growth performance of animals reared in saline land pasture would be decreased, while halophytic shrubs only accounted for 30\% of the total pasture diet. In Sprague-Dawley rats, dietary high salt (8\% salt) decreased significantly the FI and LBWG compared with the standard chow group [24]. The specific effect of high salt consumption on FI and LBWG in most animals in the experiments is controversial. Ogihara et al. [27] found that feeding rats with high salts had no significant effects on BWG and FI. The feature accountable for this contrasting statement between FI and LBWG is not clear, but could be associated with alterations in the metabolism of nutrients [24]. Wang et al. [25] indicated that consumption of high-salt diet did not exhibit drastic alterations in FI, LBWG, and the altitudes of numerous inflammatory issues. However, they observed that excess salt in the diet could hinder the host's digestive enzyme excretion, alter the biological process, the molecular function of the duodenal content, and the cell constituent, and further alter the composition of the intestinal microbiota [25]. In addition, Lins et al. [26] examined the effects of different water salinity doses $(640,3188,5740$, and $8326 \mathrm{mg} / \mathrm{L})$ on the growth performance of prepubertal male sheep. They reported that water salinity did not affect water intake or BW. Wang et al. [7] found that female mice that received high salinity water $(4 \% \mathrm{NaCl})$ exhibited a significant reduction in feed intake and water consumption compared with the control mice. Female mice exposed to high salinity in water $(4 \%)$ showed a significant reduction in growth performance [7]. These discrepancies in growth might be related to reducing feed and water intake as a result of high salinity exposure. Feed intake was markedly decreased in cattle and sheep when dietary salt levels exceeded $10 \%$, with a decrease in digestibility in sheep at $15 \%$ salt. The WI was increased to 4 liters when $100 \mathrm{~g}$ of salt were ingested by sheep and cattle. The exact molecular machinery which explains the negative influences of high salt diet on the growth performance remains unclear. High salt intake could result in alterations in some enzymes related to protein digestion and cause an upregulation of fatty acid oxidation [29]. Gut microbiota plays a major part in immunological and nutritional processes in the digestive canal [25], and changes in the composition of microbiota in the gut can affect animals and human well-being and health [30]. High salt in the diet might lead to an increase in the lipid deposition in tissues, increased lipid-metabolic enzyme expression, and glutamate metabolic pathways [31]. Scarce data on the effect of the high-salt diet on genetic changes in the digestive intestine of microbiota are nevertheless accessible. More explorations and molecular mechanisms to illustrate the undesirable effects on the performance are required. 


\section{Reproductive Variables in Males}

\subsection{Reproductive Organ Weight}

It is accepted that sperm synthesis and function are positively linked to testis weights and size, since larger testicles have a greater sperm mass. So, test size or weight might represent a possible indication of the number of sperms that will be produced. A critical factor that affected testes size certainly has direct effects on sperm production. A testis weight decrease by $22.8 \%(p<0.05)$ was achieved in rams whose feed was high salt diets $(12 \%)$ compared with those that had $0.5 \%$ salt, however, they had lower values for spermatogenic index 4 and 5, but higher values for 2 and $3(p<0.05)$ [3]. In mice, Wube, et al. [32] noticed that $3.5 \%$ or $5 \% \mathrm{NaCl}$ for $6-8 \mathrm{wk}$ decreased both spermatogenesis and testis weight. Feeding rats high salt resulted in decreased testis weights $(p<0.05)$, seminal vesicle weight, and alterations in testicular mass, which may reveal changes in seminiferous tubules [33], and finally a change in the quality and quantity of sperm [24]. This is evidence that the energetic role of testicular morphology and seminal vesicular secretion are vital for sperm function and stability of sperm chromatin [34]. Additionally, the weight of seminal vesicles is joined with the other organ weights and its secretion [35]. Hence, the lessening in weight detected possibly reflects the reduced secretions of the seminal vesicle. In prepubertal male sheep, Lins et al. [26] mentioned that water salinity at different levels had no significant effect on scrotal indices. High salt in diet or water could reduce the spermatogenesis and alter the testicular morphology leading to reduced fertility in male animals.

\subsection{Sperm Function}

Sperm function as revealed by sperm concentration, viability, morphology, and motility is an essential measure of male fertility competence, while the quality of sperm is associated with low fertility ability [36]. In rams, Fang et al. [3] reported that animals fed $12 \%$ salt had a decreased ejaculate volume and sperm concentration and an increased DNA fragmentation rate $(p<0.05)$ by $28.2,35.8$, and $417 \%$ compared with those in the control group $(0.5 \% \mathrm{NaCl})$. Adverse impacts of high salt on rams have been reported to reduce testis size and alter spermatogenic index, leading to decreased ejaculate volumes, reducing sperm count per ejaculate, and higher DNA fragmentation [3]. In rats, Adekunbi et al. [24] reported a significant decrease in epididymal sperm concentration, motility, and viability $(p<0.05)$, as a result of high diet salt $(8 \%)$ compared with the control condition. In addition, a significantly high percentage of abnormalities $(p<0.05)$ was detected in treated rats $(8$ per cent high salt diet) relative to control rats. Another study observed that rats fed the diet with high salt (8\%) had a significant increase $(p<0.05)$ in sperm abnormalities, while no significant effects were detected in sperm motility with high or low salt diet [37].

Unexpected results have been obtained by Lins et al. [26], who demonstrated that the moderate level of salt in drinking water of prepubertal male sheep exhibited beneficial influences on sperm function such as sperm motility, concentration, and vigor. However, higher abnormalities were observed in this study. This function is possibly due to the existence of water salinity. $\mathrm{Ca}^{2+}$ is responsible for the polarization and depolarization of the myofibrils of flagella, which can lead to sperm movement [26]. Moreover, these ions are imperative for sperm motility, metabolism, acrosome reaction, hyper activated motility, and fertilization [38]. Regarding apoptosis in tests, Lins et al. [26] detected a higher percentage of apoptotic spermatogonia and early spermatids when male sheep were fed with high water salinity $(8326 \mathrm{mg} / \mathrm{L})$, indicating defects in spermatogenesis. High salt intake probably increases oxygen species in cells of the renal medulla of male hamsters [39], and viable equine sperm [40], leading to promote DNA damage in the cells.

Animal studies have confirmed that suitable supplementation of minerals can improve reproductive efficiency. When there is excess salt in the diet, it causes disturbances in the mineral homeostasis in body fluids, leading to alterations in the body functions. Also, an increase in salt diets could promote infertility, accumulate lipids, liver, and renal diseases and disorders. Regarding the 
impacts of high salt diet on mineral profile, Adekunbi et al. [24] concluded that the serum content of chloride ion was significantly increased in rats fed high salt (8 percent) without any changes in other electrolytes being measured. Similarly, an earlier study of Ofem, et al. [41] detected an elevation in chloride ion level and no alteration in sodium-ion contents after feeding on high salt diet. Contrary to previous results, high intake of salt diets will result in sodium retention and extracellular fluid volume expansion, thereby elevating plasma sodium content. Morita, et al. [42] also stated that a high intake of salt did not result in major alterations in serum electrolyte levels but increased sodium excretion in the urine.

\subsection{Hormones}

Mechanisms of high salt intake on hormonal regulation have been illustrated in several studies. Significant reductions of leptin, testosterone (T), insulin, luteinizing hormone (LH), and follicle-stimulating hormone (FSH) levels were observed by feeding rams with high salt diet (12 percent) relative to controls $(p<0.05)$ [3]. Leptin is well known to have a critical function in signaling nutritional status in the mammal's centrally reproductive axis and tends to at least be a critical factor for puberty initiation, as it induces GnRH and LH releases [43]. The reduction of leptin and insulin might be attributed to the lowered body mass which is accompanied by a decrease in fat reserves. These hormones also play a major role in metabolism regulation, homeostasis, and body mass. Furthermore, the $20 \%$ salt diet of sheep reduced the peripheral level of insulin and the energy metabolism [44]. It was reported that high salt consumption declines both leptin and insulin content, independently of changes in FI or BWG [20]. Several previous studies have documented endocrine disorders in animals supplied with high salt diet, where significant decreases in plasma concentration of FSH, LH, and T were detected $[3,45]$. Regarding corticosterone, it was observed a substantial rise in corticosterone content and a remarkable reduction in the content of testosterone in rats, as influence by a high diet of salt was observed in the control group (0.5\% salt) [24]. On the other hand, Adekunbi et al. [24] suggested that LH and FSH levels have not been affected by increased salt in the diet ( $8 \%$ ) compared with control rats $(0.5 \%)$. The reduction in testosterone production caused by a high salt diet might result in a reduction in spermatogenesis and alteration in sperm quality. In addition, the Leydig cell-synthesized testosterone was found to display no significant change in gonadotropin level in response to LH stimulation despite the low testosterone level. The high salt acted against the hypothalamic-pituitary axis by interacting with LH receptors in the Leydig cells [24]. Likewise, it has been indicated that high sodium consumption enhances the secretions of glucocorticoid hormones [46] by enzyme 11betahydroxysteroid dehydrogenase type 1 (11ß-HSD1) [47]. It is well established that nutritional stress results in a high corticosterone level. Moreover, high levels of cortisol can reduce fertility [48], thus high sodium intake affects the reproductive function. Iranloye et al. [37] documented a significant improvement in FSH and testosterone levels when rat were fed with a high salt diet, however, a remarkable decrease in LH was observed when compared with controls $(p<0.05)$. This issue still needs to be investigated. Generally, a high salt diet induces a reduction in the body's fat reserves, which leads to a decrease in the cholesterol content used for the synthesis of sex hormones. Thus, a reduction in the synthesis of sex hormones such as testosterone led to decreased spermatogenesis which contributes to reduced reproductive capacity.

\subsection{Antioxidant Indices}

Oxidative stress is accompanied by sperm malfunction and low fertility in animals $[49,50]$. Malondialdehyde (MDA) is considered a critical indicator of lipid peroxidation in the cells. Mice feeding on diets with high salt (8\%) shown a marked rise in MDA level and superoxide dismutase (SOD) activities in the testis compared with controls [24]. GSH and catalase activities did not significantly differ between the high salt and control groups [24]. Similar to previous studies, Iranloye et al. [37] indicated that rats that received $\mathrm{NaCl}$ at $8 \%$ exhibited a relatively high MDA level in the epididymis compared to the controls. The activities of SOD, GSH, and CAT enzymes in testicular and epididymal 
tissues were significantly reduced by increased dietary salt in rats [37]. The high levels of MDA and SOD in the testis of rats fed a high salt diet can be attributed to free radical harm, confirming the harmful influences of the high salt intake on the reproductive patterns. Antioxidant enzymes are produced frequently in response to increased free radical concentrations; however, if antioxidant enzymes are disrupted by a high oxidative stress level, they can have harmful effects on reproduction.

\subsection{Gene Expression}

Studying the molecular mechanism of some genes related to reproduction reflects the negative impacts of high salt on sperm spermatogenesis and function. The key genes of spermatogenesis (Hsp70, $c-k i t$, and Cyclin A) were reduced markedly $(p<0.05)$ by increased salt in the ram diet $(12 \%)$, and decreased expression of sex hormone receptors, such as FSHR, AR, LHR, CYP17A1, and CYP11A1 in rams that received high salt levels [3]. However, no significant changes were observed between groups in testis key enzymes (ATPase, $\mathrm{LDH}, \mathrm{SDH}$, and AKP) [3].

Testis renin-angiotensin system (RAS) is receptive to different types of stresses and pathological conditions [51], suggesting that a disturbance of RAS may affect sperm functions and disturb the spermatogenesis process [52]. In the testis, a diet rich in salt diminished the REN's transcriptional expression; hence, local downregulation of the synthesis of AngII which reduced anions as well as fluid secretion by testis, reflecting on testis function [53]. The mechanisms responsible for the changes in reproductive health due to excessive salt intake are still not completely defined. Therefore, more studies at molecular, transcriptomics, and proteomics analyses are needed to deeply understand the negative impacts of a high salt diet on sperm functions in male animals and humans.

One explanation clarifying the changes during spermatogenesis due to a high salt diet is that it has great impacts on numerous key enzymes, such as AKP, SDH, LDH, and ATPase associated with cell proliferation and germ epithelium differentiation [54]. On the other hand, Fang et al. [3] suggested that dietary high salt had no effects on the abundance of ram testis enzymes. A high-salt diet therefore decreased the expression of main spermatogenic genes by decreasing the hormone reaction linked to spermatogenesis. Additionally, Ramaswamy and Weinbauer [55] clarified that the downregulation of the main spermatogenesis genes can be caused by Leydig cell loss or injury. The adverse effect of high salt diet on male animals is illustrated in Figure 1.

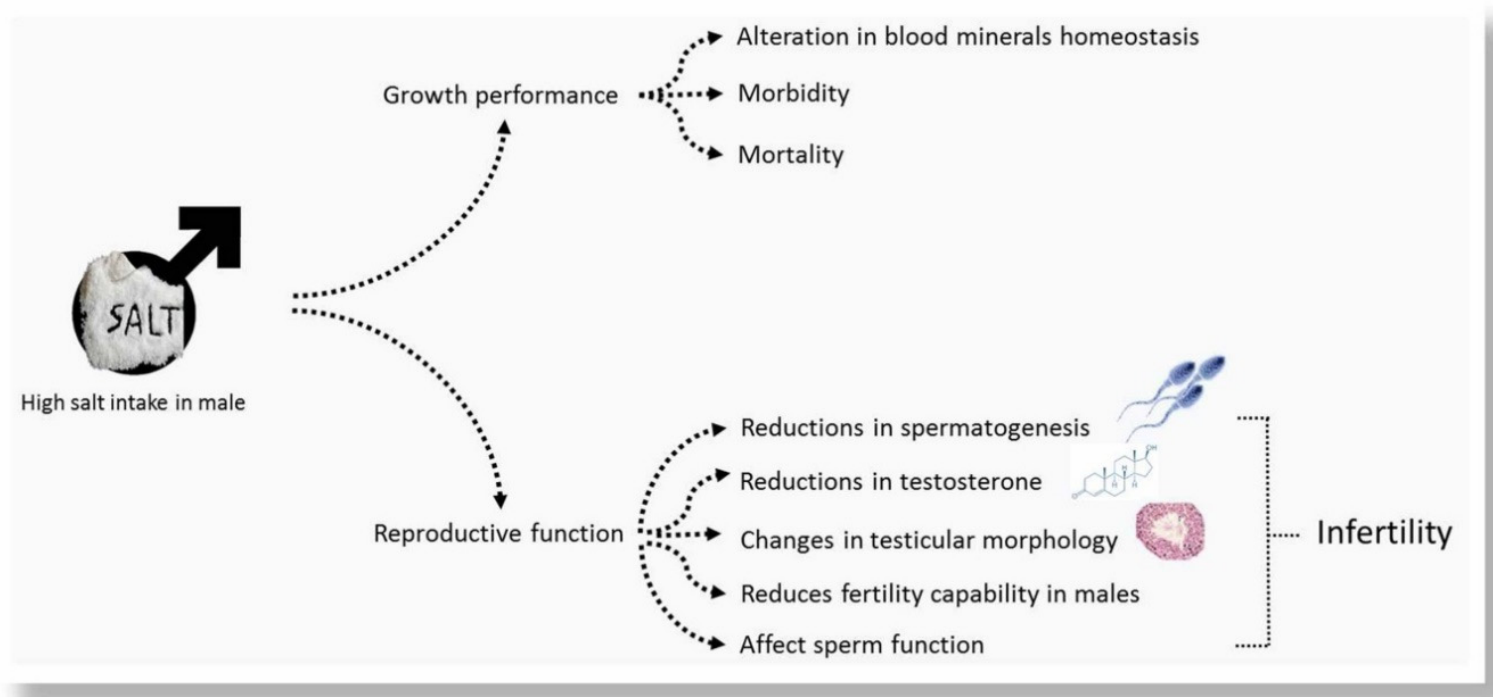

Figure 1. The adverse effect of high salt diet on male animals. 


\section{Female Reproductive Function}

\subsection{Ovarian Follicles}

The histological examination of ovaries during the development of follicles reflects the negative impacts of high salt on fertility. Female mice exposed to high salt intake (4\% in drinking water) had a fewer number of follicles at different phases than those in the control condition [7]. Moreover, a large number of atretic follicles and less corpus luteum were also found in salt-treated mice [7]. Overall, high salinity in drinking water or diet produces a fewer number in developing follicles and oocytes, and thus induce infertility in females.

\subsection{Placental Indices}

The placenta is an organ developed in the uterus throughout pregnancy. It plays a critical role in providing oxygen and nutrients to embryos and eliminates waste products from the embryo's blood. Also, it is considered as an endocrine function organ, because of its ability to secrete some hormones related to maintaining pregnancy in some animals. Interruption of placental architecture throughout pregnancy is a relevant issue in prenatal development restraint and is also a characteristic of pregnancy syndromes like preeclampsia [56]. Recently, Reynolds et al. [57] indicated that maternal consumption of salt during pregnancy modifies FI and parental metabolism together with evidence of adverse effects on meta-inflammatory forms, insulin sensitivity, and weanling offspring adiposity. Parental high salt diet induced upregulation of inflammatory cytokines such as TNF $\alpha$ and IL- $1 \beta$ together with CD68 macrophage marker in the placenta [12]. There is recent evidence suggesting that high salt consumption stimulates inflammation factors in the placenta and is related to negative effects on pregnancy via disturbance of nutrient transport to the fetus [58]. Collectively, high salt consumption through the pregnancy period alters the placental morphological patterns and induces the inflammatory response leading to a decrease in provided nutrients to the embryo development and indicative of placental insufficiency.

\subsection{Granulosa Cells}

Differentiation and proliferation of granulosa cells (GCs) are critical for normal oocyte development, follicular growth, ovulation, and latinization [59]. High salinity is becoming an important environmental factor that has harmful influences on ovarian cells and consequently diminishes fertility is most mammal species [7]. Dysfunction of GCs due to any environmental or physiological issues leads to disordered ovarian follicle and oocyte development [60]. Phospho-histone H3 (PH3) is the main indicator as a biomarker for cell cycle and proliferation in stage G2 and mitosis (PH3 stains the condensed chromatin just before chromosomal segregation). Under high salinity, Wang et al. [7] detected less $\mathrm{PH} 3+$ granulosa cells in the follicles in comparison with the controls. Moreover, it has been reported that follicle-stimulating hormone receptor (FSH-R) protein in granulosa cells was suppressed under high salinity compared with a normal physiological range of salt [7]. High salinity exposure also decreased the abundance of PCNA, another measure of cell proliferation, while upregulated the cleaved caspase-3 [7]. Cumulative results indicated that one of the main explanations for the infertility phenomenon in mammalian species is the undesirable impact of high salinity on the growth and apoptosis of granulosa cells. 


\subsection{Hormones}

In female mice, the serum concentrations of progesterone, testosterone, and estradiol were not changed in mice fed with high salt-supplemented diets (4\% in drinking water) compared with the control group [7]. However, high salinity is also reported to inhibit FSH secretion by the hypothalamus, which disrupts follicular development. The potential for high salinity to influence the role of the granulosa cells by controlling FSH-R expression remains to be studied in the future. Wang et al. [7] reported an elevation in sodium and chloride ions after exposure to high salinity water (4\% in drinking water of female mice), representing its adverse effect on mineral balance in the body. The adverse effect of high salt diet on female animals is illustrated in Figure 2. Impacts of high salts on animals are briefed in Table 1.

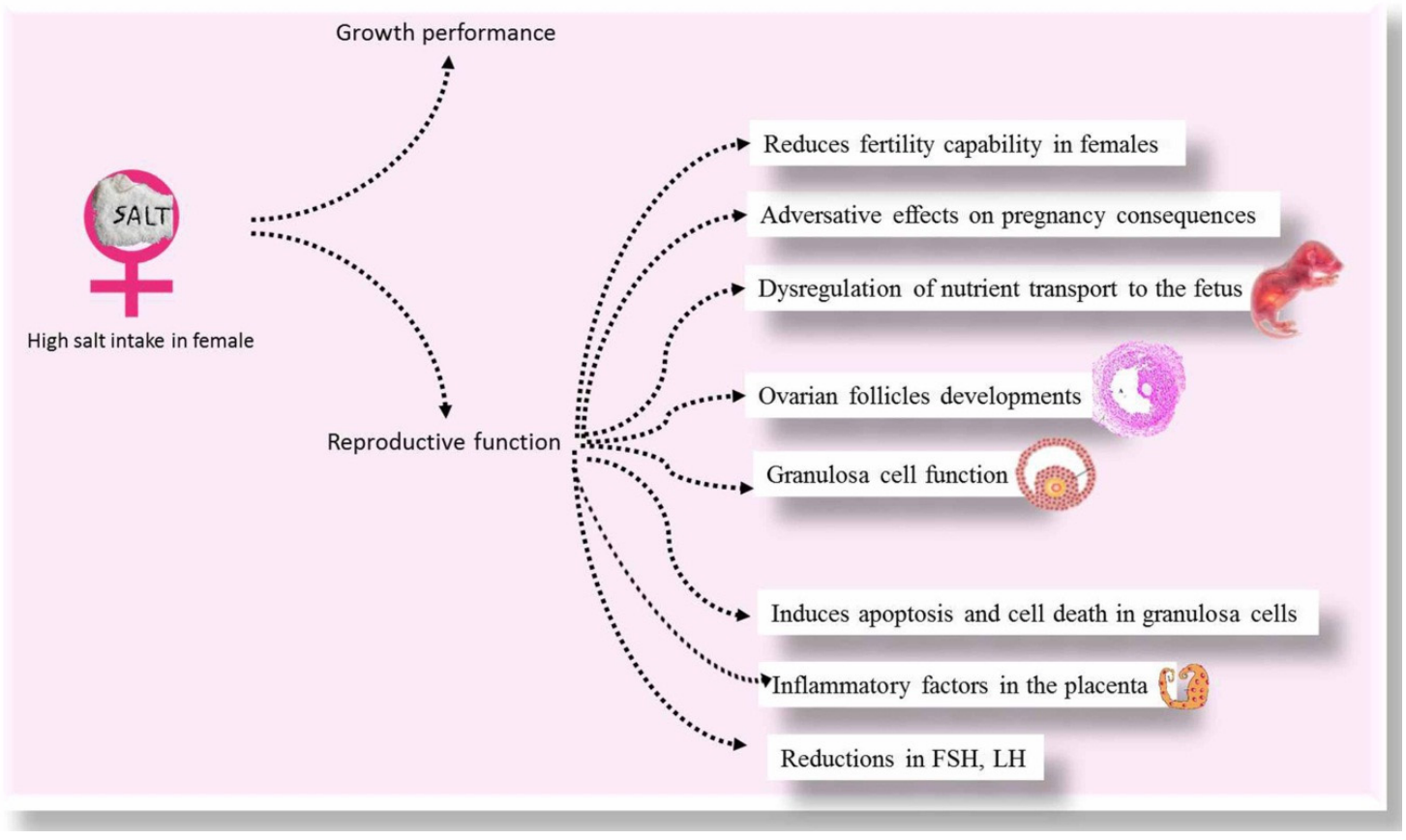

Figure 2. The adverse effect of high salt diet on female animals.

\section{Consequences of In Vitro Fertilization}

The female mice exposed to a diet with high salinity have been documented to be less fertile than the control ones [7]. This suggested that high salt treatment delays fertility during the mice's growth period. For in vitro fertilization, it has been indicated that the cleavage rate was not affected by high diet salt in rams (12\%), however, the hatching rate was lower by $70 \%$ in the $12 \%$-salt group relative to the control one $(p<0.05)$ [3]. Increased DNA fragmentation show serious long-term effects on embryo development and offspring health [45], while having a diet with only 12 percent of salt did not alter the cleavage level, but had a negative impact on the hatching rate in sheep [3]. 
Table 1. Impacts of high salt diets on animals.

\begin{tabular}{|c|c|c|c|c|}
\hline Items & Species & Dose & Main Findings & References \\
\hline \multirow{6}{*}{ 1- Growth performance } & Sheep & $(13 \% \mathrm{NaCl})$ diet during prenatal life & Modified thirst level, and blunted aldosterone reaction to oral salt levels. & [4] \\
\hline & Sheep & $80 \mathrm{~g} / \mathrm{kg} \mathrm{DM}$ & - Reduced feed consumption, liveweight gain, digestion, and wool quality. & [20] \\
\hline & Merino ewes & $(14 \% \mathrm{NaCl})$ diet during prenatal life & $\begin{array}{l}\text { - Lower renin activity in lambs. } \\
\text { - K concentrat content of the milk was changed. } \\
\text { - } \quad \text { Plasma Na of ewes hed by } 10 \text { percent. } \\
\text { - }\end{array}$ & [21] \\
\hline & C57BL/6J mice & $3.15 \% \mathrm{NaCl}$ & $\begin{array}{l}\text { - Improved the ratio of Firmicutes/Bacteroidetes and Lachnospiraceae and Ruminococcus abundances. } \\
\text { - Reduced Lactobacillus abundance. } \\
\text { In the high-salt diet group, } 20 \text { low-abundance proteins were identified in duodenal content, which } \\
\text { involved digestive enzymes and pancreatic secretion. } \\
\text { - No substantially differentiated proteins have been observed in colonic, cecal, and jejunal contents. } \\
\text { - There was an increased abundance of five proteins (trigger factor, undecaprenyl-diphosphatase, } \\
\text { cytidylate kinase, transporter, and 6-phosphogluconate dehydrogenase). } \\
\text { Two proteins were over-expressed including, PBSX phage manganese-containing catalase and acetyl } \\
\text { glutamate kinase. }\end{array}$ & [25] \\
\hline & Merino sheep & ( $20 \% \mathrm{NaCl}$ of dry matter) & $\begin{array}{l}\text { - Eating large quantities of salt, reduce the amount of voluntary feed as well as the circulation of } \\
\text { insulin and glucose concentrations. } \\
\text { - The high intakes of salt did not affect live weight and leptin concentrations in particular, but were } \\
\text { reduced as a result of the decreased intake. } \\
\text { - Secretion of cortisol has not been affected. Although insulin and glucose have been affected by salt } \\
\text { intakes (in addition to the effects of a decreased dietary intake), insulin intake is anticipated to } \\
\text { decrease instead of increase consumption. }\end{array}$ & [44] \\
\hline & Endothelin-1 knockout mice. & $8 \% \mathrm{NaCl}$ diet & $\begin{array}{l}\text { - High salt diet significantly improved the sodium excretion in urine and fractional excretion of } \\
\text { sodium (FENa). } \\
\text { - The amount of circulating plasma, serum electrolytes, and creatinine clearance, or systemic blood } \\
\text { pressure were not affected. } \\
\text { - Excretion of urinary norepinephrine and normetanephrine has increased significantly, suggesting } \\
\text { that salt loads may enhance sympathetic nerve function in normal mice. }\end{array}$ & [42] \\
\hline $\begin{array}{l}\text { 2- Reproductive functions of } \\
\text { male }\end{array}$ & Merino rams & $12 \% \mathrm{NaCl}$ diet & $\begin{array}{l}\text { - Smaller testes, reductions in spermatogenesis, lower ejaculate volumes, and decreased } \\
\text { sperm concentration. } \\
\text { - In vitro fertilization, hatching rate was lower for sperm from rams on the high-salt diet. } \\
\text { - } \quad \text { Reduced the plasma levels of sex (FSH, LH, and T) and metabolic (insulin and leptin) hormones. } \\
\text { as well as major spermatogenesesis genes (Cyclin A, Hsp70, and c-kit). }\end{array}$ & [3] \\
\hline
\end{tabular}


Table 1. Cont.

\begin{tabular}{|c|c|c|c|c|}
\hline Items & Species & Dose & Main Findings & References \\
\hline & Rats & $8 \%$ salt diet & $\begin{array}{l}\text { - The viability, concentration, morphology, and motility of sperm have been changed substantially. } \\
\text { - The serum level of testosterone was significantly reduced. } \\
\text { - Salt intake resulted in an increase in serum corticosterone concentration. } \\
\text { - In treated rats, SOD was significantly improved compared with control. }\end{array}$ & [24] \\
\hline & Rats & $8 \%$ salt diet & $\begin{array}{l}\text { - Increased sperm count was observed in the high salt diet-treated rats. Increased abnormal sperm } \\
\text { cells and increased epididymal oxidative stress. } \\
\text { - In high salt diet-treated rats, FSH and testosterone concentrations increased, whereas LH } \\
\text { concentrations decreased. }\end{array}$ & [37] \\
\hline & Golden spiny mice & $5 \%$ & $\begin{array}{l}\text { - The osmolarity of urine exhibited a remarkable rise in salinity below } 5 \text { percent. } \\
\text { - Incris mass and spermatogenesis have decreased considerably. } \\
\text { - Recovering subjects quicktantially reduced body weight. } \\
\text { initial values. Testis weight and spermatogenesis, howeverer, showed no recovery. }\end{array}$ & [32] \\
\hline & Common spiny mice & $3.5 \%$ & $\begin{array}{l}\text { - The osmolarity of the urine revealed a significant rise of less than } 3.5 \text { percent. } \\
\text { - Increase in salinity did not reduce body mass in } A \text {. cahirinus. } \\
\text { Recovering subjects quickly regained their body weight and after only four weeks they exceeded } \\
\text { initial values. Testis weight and spermatogenesis, however, showed no recovery. }\end{array}$ & [32] \\
\hline \multirow[t]{2}{*}{ 3- $\operatorname{Re}$} & Mouse & $4 \% \mathrm{NaCl}$ water & $\begin{array}{l}\text { - Prevented follicle growth by causing theca and granulosa cells apoptosis and suppressed granulosa } \\
\text { cell proliferation. }\end{array}$ & [7] \\
\hline & Merino ewes & ( $\mathrm{NaCl} 13 \%$ of dry matter) & $\begin{array}{l}\text { - Lower levels of insulin and leptin. } \\
\text { - During gestation, the concentration of T3 varied, leading to lower levels in the high-salt group during } \\
\text { the first third of pregnancy and higher levels in the final third of pregnancy. } \\
\text { - In the first two-thirds of pregnancy, the concentration of T4 was less in ewes eating high-salt diet. } \\
\text { No significant effects of high salt consumption have been observed on the rates of pregnancy, weights } \\
\text { of lamb birth, or composition of milk. }\end{array}$ & [22] \\
\hline
\end{tabular}




\section{Conclusions}

Generally, the use of halophytic plants in animal feeding is mostly associated with a reduction in reproductive performance and health problems. High salt intake may lead to decreased spermatogenesis, alterations in testicular morphology and declined spermatogenic function (concentration, viability, abnormalities, and motility). Furthermore, high salt diet reduces the synthesis of testosterone, FSH, LH, and leptin. Animal exposure to high salts increases the oxidative stress and induces the injury of the sperms and consequently reducing the reproductive performance in males. Additionally, studies on female animals revealed that high salt diet produces a smaller number of ovarian follicles, reduces cell proliferation, and induces apoptosis in granulosa cells. High salt intake also increases the circulating inflammatory factors that promote placenta inflammation and is linked to adverse effects of pregnancy by dysregulatory transport of nutrients to the fetus. Animal models are useful substitutes for humans in studies for both etiology and therapeutic interventions. Considering this, necessary steps should be provided, with the rise of salt intake in the western diet and takeaway foods, which might have detrimental effects on human fertility. The mechanism of negative impacts of high salt in western diets and fast foods in humans needs more investigations because it might be responsible for the low fertility nowadays.

Author Contributions: All authors substantially contributed to the conception, design, analysis, and interpretation of data, verification and approval of the final version of the manuscript, and agreed to be accountable for its contents. All authors have read and agreed to the published version of the manuscript.

Funding: This research received no external funding.

Acknowledgments: This research was funded by the Deanship of Scientific Research at Princess Nourah bint Abdulrahman University through the Fast-track Research Funding Program.

Conflicts of Interest: The authors declare no conflict of interest.

\section{References}

1. Abd El-Hack, M.E.; Alagawany, M.; Arif, M.; Emam, M.; Saeed, M.; Arain, M.A.; Siyal, F.A.; Patra, A.; Elnesr, S.S.; Khan, R.U. The uses of microbial phytase as a feed additive in poultry nutrition-A review. Ann. Anim. Sci. 2018, 18, 639-658. [CrossRef]

2. Abd El-Hack, M.E.; Samak, D.H.; Noreldin, A.E.; Arif, M.; Yaqoob, H.S.; Swelum, A.A. Towards saving freshwater: Halophytes as unconventional feedstuffs in livestock feed: A review. Environ. Sci. Pollut. Res. 2018, 25, 14397-14406. [CrossRef]

3. Fang, Y.; Zhong, R.; Sun, X.; Zhou, D. High salt diet decreases reproductive performance in rams and down-regulates gene expression of some components of the renin-angiotensin system in the testis. Theriogenology 2018, 107, 127-133. [CrossRef]

4. Digby, S.; Masters, D.; Blache, D.; Hynd, P.; Revell, D. Offspring born to ewes fed high salt during pregnancy have altered responses to oral salt loads. Animal 2010, 4, 81-88. [CrossRef]

5. Ohta, Y.; Tsuchihashi, T.; Kiyohara, K.; Oniki, H. High salt intake promotes a decline in renal function in hypertensive patients: A 10-year observational study. Hypertens. Res. 2013, 36, 172. [CrossRef]

6. Cohen, A.; Roe, F. Review of risk factors for osteoporosis with particular reference to a possible aetiological role of dietary salt. Food Chem. Toxicol. 2000, 38, 237-253. [CrossRef]

7. Wang, G.; Yeung, C.-K.; Zhang, J.-L.; Hu, X.-W.; Ye, Y.-X.; Yang, Y.-X.; Li, J.-C.; Lee, K.K.H.; Yang, X.; Wang, L.-J. High salt intake negatively impacts ovarian follicle development. Ann. Anat. Anat. Anz. 2015, 200, $79-87$. [CrossRef]

8. Damasio, P.C.; Amaro, C.R.; Cunha, N.B.; Pichutte, A.C.; Goldberg, J.; Padovani, C.R.; Amaro, J.L. The role of salt abuse on risk for hypercalciuria. Nutr. J. 2011, 10, 3.

9. Faraco, G.; Brea, D.; Garcia-Bonilla, L.; Wang, G.; Racchumi, G.; Chang, H.; Buendia, I.; Santisteban, M.M.; Segarra, S.G.; Koizumi, K. Dietary salt promotes neurovascular and cognitive dysfunction through a gut-initiated TH17 response. Nat. Neurosci. 2018, 21, 240. [CrossRef] 
10. Aguiar, S.L.F.; Miranda, M.C.G.; Guimarães, M.A.F.; Santiago, H.C.; Queiroz, C.P.; Cunha, P.d.S.; Cara, D.C.; Foureaux, G.; Ferreira, A.J.; Cardoso, V.N. High-salt diet induces IL-17-dependent gut inflammation and exacerbates colitis in mice. Front. Immunol. 2018, 8, 1969. [CrossRef]

11. Yi, B.; Titze, J.; Rykova, M.; Feuerecker, M.; Vassilieva, G.; Nichiporuk, I.; Schelling, G.; Morukov, B.; Choukèr, A. Effects of dietary salt levels on monocytic cells and immune responses in healthy human subjects: A longitudinal study. Transl. Res. 2015, 166, 103-110. [CrossRef]

12. Reynolds, C.M.; Vickers, M.H.; Harrison, C.J.; Segovia, S.A.; Gray, C. Maternal high fat and/or salt consumption induces sex-specific inflammatory and nutrient transport in the rat placenta. Physiol. Rep. 2015, 3, e12399. [CrossRef]

13. Farquhar, W.B.; Edwards, D.G.; Jurkovitz, C.T.; Weintraub, W.S. Dietary sodium and health: More than just blood pressure. J. Am. Coll. Cardiol. 2015, 65, 1042-1050. [CrossRef]

14. Frisoli, T.M.; Schmieder, R.E.; Grodzicki, T.; Messerli, F.H. Salt and hypertension: Is salt dietary reduction worth the effort? Am. J. Med. 2012, 125, 433-439. [CrossRef]

15. Appel, L.J.; Frohlich, E.D.; Hall, J.E.; Pearson, T.A.; Sacco, R.L.; Seals, D.R.; Sacks, F.M.; Smith, S.C., Jr.; Vafiadis, D.K.; Van Horn, L.V. The importance of population-wide sodium reduction as a means to prevent cardiovascular disease and stroke: A call to action from the American Heart Association. Circulation 2011, 123, 1138-1143. [CrossRef]

16. Boon, C.S.; Taylor, C.L.; Henney, J.E. Strategies to Reduce Sodium Intake in the United States; National Academies Press: Washington, DC, USA, 2010.

17. Kotchen, T.A.; Cowley, A.W., Jr.; Frohlich, E.D. Salt in health and disease-A delicate balance. N. Engl. J. Med. 2013, 368, 1229-1237. [CrossRef]

18. Nicholls, M.G. Population-wide dietary sodium restriction: A cautious view. Curr. Hypertens. Rep. 2011, 13, 325. [CrossRef]

19. Oh, Y.S.; Appel, L.J.; Galis, Z.S.; Hafler, D.A.; He, J.; Hernandez, A.L.; Joe, B.; Karumanchi, S.A.; Maric-Bilkan, C.; Mattson, D. National Heart, Lung, and Blood Institute Working Group report on salt in human health and sickness: Building on the current scientific evidence. Hypertension 2016, 68, 281-288. [CrossRef]

20. Masters, D.G.; Rintoul, A.J.; Dynes, R.A.; Pearce, K.L.; Norman, H.C. Feed intake and production in sheep fed diets high in sodium and potassium. Aust. J. Agric. Res. 2005, 56, 427-434. [CrossRef]

21. Chadwick, M.; Williams, I.; Vercoe, P.; Revell, D. Feeding pregnant ewes a high-salt diet or saltbush suppresses their offspring's postnatal renin activity. Animal 2009, 3, 972-979. [CrossRef]

22. Digby, S.; Masters, D.; Blache, D.; Blackberry, M.; Hynd, P.; Revell, D. Reproductive capacity of Merino ewes fed a high-salt diet. Animal 2008, 2, 1353-1360. [CrossRef]

23. López, A.; Arroquy, J.I.; Juárez Sequeira, A.; García, M.; Nazareno, M.; Coria, H.; Distel, R. Effect of protein supplementation on tropical grass hay utilization by beef steers drinking saline water. J. Anim. Sci. 2014, 92, 2152-2160. [CrossRef]

24. Adekunbi, D.; Ogunsola, O.; Oyelowo, O.; Aluko, E.; Popoola, A.; Akinboboye, O. Consumption of high sucrose and/or high salt diet alters sperm function in male Sprague-Dawley rats. Egypt. J. Basic Appl. Sci. 2016, 3, 194-201.

25. Wang, C.; Huang, Z.; Yu, K.; Ding, R.; Ye, K.; Dai, C.; Xu, X.; Zhou, G.; Li, C. High-salt diet has a certain impact on protein digestion and gut microbiota: A sequencing and proteome combined study. Front. Microbiol. 2017, 8, 1838.

26. Lins, T.; Menezes, V.; Barberino, R.; Costa, S.; Santos, N.; Nascimento, T.; Queiroz, M.; Cordeiro, M.; Ribeiro, L.; Araujo, G. Sperm quality, and morphology and apoptosis of germinal epithelium cells of ram lambs receiving water of different salinities. Anim. Prod. Sci. 2018, 58, 1608-1614.

27. Ogihara, T.; Asano, T.; Ando, K.; Chiba, Y.; Sekine, N.; Sakoda, H.; Anai, M.; Onishi, Y.; Fujishiro, M.; Ono, H. Insulin resistance with enhanced insulin signaling in high-salt diet-fed rats. Diabetes 2001, 50, 573-583. [CrossRef]

28. Norman, H.C.; Freind, C.; Masters, D.G.; Rintoul, A.J.; Dynes, R.A.; Williams, I.H. Variation within and between two saltbush species in plant composition and subsequent selection by sheep. Aust. J. Agric. Res. 2004, 55, 999-1007. [CrossRef]

29. Obih, P.O.; Oyekan, A. Proteomic Analysis of Salt-Induced Changes in Protein Expression in PPAR $\alpha$ Null Mice. Pharmacol. Pharm. 2014, 5, 996. [CrossRef] 
30. Clemente, J.C.; Ursell, L.K.; Parfrey, L.W.; Knight, R. The impact of the gut microbiota on human health: An integrative view. Cell 2012, 148, 1258-1270. [CrossRef]

31. Daniel, H.; Gholami, A.M.; Berry, D.; Desmarchelier, C.; Hahne, H.; Loh, G.; Mondot, S.; Lepage, P.; Rothballer, M.; Walker, A. High-fat diet alters gut microbiota physiology in mice. ISME J. 2014, 8, 295.

32. Wube, T.; Haim, A.; Fares, F. Effect of increased dietary salinity on the reproductive status and energy intake of xeric and mesic populations of the spiny mouse, Acomys. Physiol. Behav. 2009, 96, 122-127. [CrossRef]

33. Sellers, R.S.; Mortan, D.; Michael, B.; Roome, N.; Johnson, J.K.; Yano, B.L.; Perry, R.; Schafer, K. Society of Toxicologic Pathology position paper: Organ weight recommendations for toxicology studies. Toxicol. Pathol. 2007, 35, 751-755. [CrossRef] [PubMed]

34. Gonzales, G.F. Function of seminal vesicles and their role on male fertility. Asian J. Androl. 2001, 3, $251-258$.

35. Mukerjee, B.; Rajan, T. Morphometric study of seminal vesicles of rat in normal health and stress conditions. J. Anat. Soc. India 2006, 55, 33-36.

36. Basnet, P.; Hansen, S.A.; Olaussen, I.K.; Hentemann, M.A.; Acharya, G. Changes in the semen quality among 5739 men seeking infertility treatment in Northern Norway over past 20 years (1993-2012). J. Reprod. Biotechnol. Fertil. 2016, 5, 2058915816633539. [CrossRef]

37. Iranloye, B.O.; Oludare, G.O.; Morakinyo, A.O.; Esume, N.A.; Ekeh, L.C. Reproductive parameters and oxidative stress status of male rats fed with low and high salt diet. J. Hum. Reprod. Sci. 2013, 6, 267. [CrossRef]

38. Rahman, M.S.; Kwon, W.-S.; Pang, M.-G. Calcium influx and male fertility in the context of the sperm proteome: An update. BioMed Res. Int. 2014, 2014, 841615. [CrossRef]

39. Burg, M.B.; Ferraris, J.D.; Dmitrieva, N.I. Cellular response to hyperosmotic stresses. Physiol. Rev. 2007, 87, 1441-1474. [CrossRef]

40. Burnaugh, L.; Ball, B.; Sabeur, K.; Thomas, A.; Meyers, S.A. Osmotic stress stimulates generation of superoxide anion by spermatozoa in horses. Anim. Reprod. Sci. 2010, 117, 249-260. [CrossRef]

41. Ofem, O.; Ani, E.; Okoi, O.; Effiang, A.; Eno, A.; Ibu, J. Effect of Viscum album (mistletoe) extract on some serum electrolytes, organ weight and cytoarchitecture of the heart, kidney and blood vessels in high salt fed rats. Internet J. Nutr. Wellness 2006, 4, 1-10.

42. Morita, H.; Kurihara, H.; Kurihara, Y.; Kuwaki, T.; Shindo, T.; Oh-hashi, Y.; Kumada, M.; Yazaki, Y. Responses of blood pressure and catecholamine metabolism to high salt loading in endothelin-1 knockout mice. Hypertens. Res. 1999, 22, 11-16. [CrossRef]

43. Zieba, D.A.; Amstalden, M.; Williams, G. Regulatory roles of leptin in reproduction and metabolism: A comparative review. Domest. Anim. Endocrinol. 2005, 29, 166-185. [CrossRef]

44. Blache, D.; Grandison, M.J.; Masters, D.G.; Dynes, R.A.; Blackberry, M.A.; Martin, G.B. Relationships between metabolic endocrine systems and voluntary feed intake in Merino sheep fed a high salt diet. Aust. J. Exp. Agric. 2007, 47, 544-550. [CrossRef]

45. Evenson, D.; Jost, L. Sperm chromatin structure assay is useful for fertility assessment. Methods Cell Sci. 2000, 22, 169-189. [CrossRef] [PubMed]

46. Baudrand, R.; Campino, C.; Carvajal, C.; Olivieri, O.; Guidi, G.; Faccini, G.; Vöhringer, P.; Cerda, J.; Owen, G.; Kalergis, A. High sodium intake is associated with increased glucocorticoid production, insulin resistance and metabolic syndrome. Clin. Endocrinol. 2014, 80, 677-684. [CrossRef]

47. Usukura, M.; Zhu, A.; Yoneda, T.; Karashima, S.; Yagi, K.; Yamagishi, M.; Takeda, Y. Effects of a high-salt diet on adipocyte glucocorticoid receptor and 11- $\beta$ hydroxysteroid dehydrogenase 1 in salt-sensitive hypertensive rats. Steroids 2009, 74, 978-982. [CrossRef]

48. Ziegler, T.E.; Scheffler, G.; Snowdon, C.T. The relationship of cortisol levels to social environment and reproductive functioning in female cotton-top tamarins, Saguinus oedipus. Horm. Behav. 1995, 29, 407-424. [CrossRef]

49. Mostafa, T.; Anis, T.; Imam, H.; El-Nashar, A.; Osman, I. Seminal reactive oxygen species-antioxidant relationship in fertile males with and without varicocele. Andrologia 2009, 41, 125-129. [CrossRef] [PubMed]

50. Hassan, E.; El-Neweshy, M.; Hassan, M.; Noreldin, A. Thymoquinone attenuates testicular and spermotoxicity following subchronic lead exposure in male rats: Possible mechanisms are involved. Life Sci. 2019, 230, 132-140. [CrossRef] [PubMed]

51. Leung, P.; Sernia, C. The renin-angiotensin system and male reproduction: New functions for old hormones. J. Mol. Endocrinol. 2003, 30, 263-270. [CrossRef] 
52. Herr, D.; Bekes, I.; Wulff, C. Local renin-angiotensin system in the reproductive system. Front. Endocrinol. 2013, 4, 150. [CrossRef] [PubMed]

53. Leung, P.; Carlsson, P. Tissue renin-angiotensin system: Its expression, localization, regulation and potential role in the pancreas. J. Mol. Endocrinol. 2001, 26, 155-164. [CrossRef] [PubMed]

54. Brito, L.F.; Barth, A.D.; Rawlings, N.C.; Wilde, R.E.; Crews, D.H., Jr.; Mir, P.S.; Kastelic, J.P. Effect of nutrition during calfhood and peripubertal period on serum metabolic hormones, gonadotropins and testosterone concentrations, and on sexual development in bulls. Domest. Anim. Endocrinol. 2007, 33, 1-18. [CrossRef]

55. Ramaswamy, S.; Weinbauer, G.F. Endocrine control of spermatogenesis: Role of FSH and LH/testosterone. Spermatogenesis 2014, 4, e996025. [CrossRef] [PubMed]

56. Kim, D.W.; Young, S.L.; Grattan, D.R.; Jasoni, C.L. Obesity during pregnancy disrupts placental morphology, cell proliferation, and inflammation in a sex-specific manner across gestation in the mouse. Biol. Reprod. 2014, 90, 1-11. [CrossRef] [PubMed]

57. Reynolds, C.M.; Vickers, M.H.; Harrison, C.J.; Segovia, S.A.; Gray, C. High fat and/or high salt intake during pregnancy alters maternal meta-inflammation and offspring growth and metabolic profiles. Physiol. Rep. 2014, 2, e12110. [CrossRef] [PubMed]

58. Lager, S.; Samulesson, A.M.; Taylor, P.D.; Poston, L.; Powell, T.L.; Jansson, T. Diet-induced obesity in mice reduces placental efficiency and inhibits placental mTOR signaling. Physiol. Rep. 2014, 2, e00242. [CrossRef]

59. Eppig, J.J. Oocyte control of ovarian follicular development and function in mammals. Reproduction 2001, 122, 829-838. [CrossRef]

60. Tatone, C.; Amicarelli, F.; Carbone, M.C.; Monteleone, P.; Caserta, D.; Marci, R.; Artini, P.G.; Piomboni, P.; Focarelli, R. Cellular and molecular aspects of ovarian follicle ageing. Hum. Reprod. Update 2008, 14, 131-142. [CrossRef]

(C) 2020 by the authors. Licensee MDPI, Basel, Switzerland. This article is an open access article distributed under the terms and conditions of the Creative Commons Attribution (CC BY) license (http://creativecommons.org/licenses/by/4.0/). 